\title{
Analysis of factors contributing to postoperative body weight change in patients with gastric cancer: Based on generalized estimation equation
}

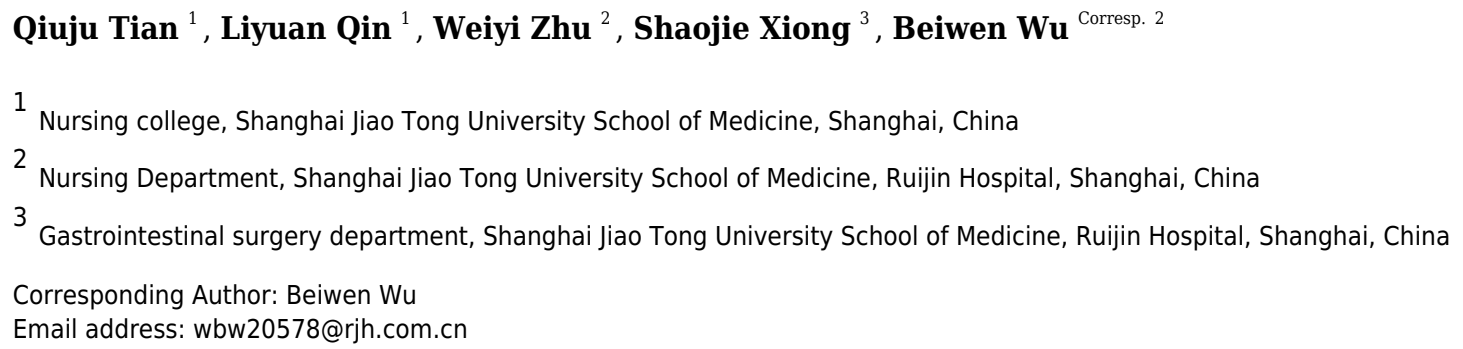

Aims. The study aimed to explore factors contributing to body weight change over time in gastric cancer patients after gastrectomy, in order to find risk factors to implement nutritional intervention beforehand. Methods. Consecutively a cohort of gastric cancer patients who were treated with gastrectomy from January to March 2019 at a university affiliated hospital in Shanghai were identified in this study. Demographics, disease related information, nutrition knowledge, attitude, and practice score were collected before gastrectomy. In addition, body weight before surgery (T0), body weight at one month (T1), two months (T2), and three months (T3) after gastrectomy were recorded. Generalized estimation equation was used to describe body weight change and analyze factors contributing to body weight change after surgery. Results. There were 49 patients recruited in the study. Patient's body weight decreased by $9.2 \%$ at T1 (Wald c ${ }^{2}=271.173$, $\mathrm{P} \& \lambda \tau ; 0.001), 11.0 \%$ at T2 (Wald $\chi^{2}=277.267, \mathrm{P} \& \lambda \tau ; 0.001$ ), and $11.4 \%$ at T3 compared to baseline at T0 (Wald $\mathrm{c}^{2}=284.076, \mathrm{P} \& \lambda \tau ; 0.001$ ). The results of GEE for multivariable analysis showed that surgery type (Wald $\left.\mathrm{c}^{2}=6.027, \mathrm{P}=0.014\right)$ and preoperative BMI (Wald $c^{2}=12.662, P=0.005$ ) were contributing factors of body weight change. Compared with distal gastrectomy patients, total gastrectomy patients experienced greater body weight loss ( $B=2.8 \%, P=0.014)$. Compared with patient with $B M I \& \lambda \tau ; 18.5 \mathrm{~kg} / \mathrm{m}^{2}$, patients with $\mathrm{BMI} \geq 25 \mathrm{~kg} / \mathrm{m}^{2}$ experienced greater body weight loss ( $\mathrm{B}=4.5 \% \mathrm{P}=0.026$ ). Conclusion. Gastric cancer patients experienced significant weight loss during 3 months after gastrectomy. Total gastrectomy and BMI $\geq 25 \mathrm{~kg} / \mathrm{m}^{2}$ were risk factors to postoperative body weight loss for GC patients. The results suggested hinted that clinician 
should pay attention to postoperative nutrition status of patient undergoing total gastrectomy and obesity patients. 
1 Analysis of factors contributing to postoperative body weight 2 change in patients with gastric cancer: Based on generalized 3 estimation equation

4

Qiuju Tian ${ }^{1,2}$, Liyuan Qin ${ }^{1,2}$, Weiyi Zhu ${ }^{2}$, Shaojie Xiong ${ }^{3}$, Beiwen $\mathrm{Wu}^{2}$

${ }^{1}$ Nursing College, Shanghai Jiao Tong University School of Medicine, Shanghai, China

${ }^{2}$ Nursing Department, Shanghai Jiao Tong University School of Medicine, Ruijin Hospital, Shanghai, China

${ }^{3}$ Gastrointestinal Surgery Department, Shanghai Jiao Tong University School of Medicine, Ruijin Hospital, Shanghai, China

Corresponding Author:

Beiwen $\mathrm{Wu}^{2}$

No. 197 Ruijin Er Rd, Shanghai, 210025, China

Email address: gaoan2005new@163.com

\section{Abstract}

Aims. The study aimed to explore factors contributing to body weight change over time in gastric cancer patients after gastrectomy, in order to find risk factors to implement nutritional intervention beforehand.

Methods. Consecutively a cohort of gastric cancer patients who were treated with gastrectomy from January to March 2019 at a university affiliated hospital in Shanghai were identified in this study. Demographics, disease related information, nutrition knowledge, attitude, and practice score were collected before gastrectomy. In addition, body weight before surgery (T0), body weight at one month (T1), two months (T2), and three months (T3) after gastrectomy were recorded. Generalized estimation equation was used to describe body weight change and analyze factors contributing to body weight change after surgery.

Results. There were 49 patients recruited in the study. Patient's body weight decreased by $9.2 \%$ at T1 (Wald $\chi^{2}=271.173, \mathrm{P}<0.001$ ), $11.0 \%$ at T2 (Wald $\chi^{2}=277.267, \mathrm{P}<0.001$ ), and $11.4 \%$ at T3 compared to baseline at T0 (Wald $\chi^{2}=284.076, \mathrm{P}<0.001$ ). The results of GEE for multivariable analysis showed that surgery type (Wald $\chi^{2}=6.027, \mathrm{P}=0.014$ ) and preoperative BMI (Wald $\chi^{2}=$ $12.662, \mathrm{P}=0.005)$ were contributing factors of body weight change. Compared with distal gastrectomy patients, total gastrectomy patients experienced greater body weight loss $(\mathrm{B}=2.8 \%$, $\mathrm{P}=0.014)$. Compared with patient with $\mathrm{BMI}<18.5 \mathrm{~kg} / \mathrm{m}^{2}$, patients with $\mathrm{BMI} \geq 25 \mathrm{~kg} / \mathrm{m}^{2}$ experienced greater body weight loss $(\mathrm{B}=4.5 \% \mathrm{P}=0.026)$.

Conclusion. Gastric cancer patients experienced significant weight loss during 3 months after gastrectomy. Total gastrectomy and BMI $\geq 25 \mathrm{~kg} / \mathrm{m}^{2}$ were risk factors to postoperative body 
40

41

42

43

44

45

46

47

48

49

50

51

52

53

54

55

56

57

58

59

60

61

62

63

64

65

66

67

68

69

70

71

72

73

74

75

76

77

78

79

weight loss for GC patients. The results suggested hinted that clinician should pay attention to postoperative nutrition status of patient undergoing total gastrectomy and obesity patients.

\section{Introduction}

Although the morbidity and mortality of gastric cancer (GC) have been decreased recent years globally, new cases and deaths from GC in China are still on a relatively high level, accounting for $42.6 \%$ new cases and $45 \%$ deaths from GC worldwide (Ferlay et al. 2015). As the development of medical science, GC patients have experienced longer survival (Allemani et al. 2018). In China, five-year survival rate for GC increased from $27.4 \%$ in 2003 to $35.1 \%$ in 2015(Zeng et al. 2018). Surgical resection is considered to be the only radical treatment for GC combined with neoadjuvant therapy or not. Body weight loss is a prevalent problem among patients after surgical treatment. A study in Japan followed up 105 patients with stage I GC undergoing open distal gastrectomy (ODG) or laparoscopy-assisted distal gastrectomy (LADG), and found that body weight loss at 1 week, 1 month, and 3 months were $-3.0 \%,-4.9 \%$, and $-5.4 \%$, respectively in patients who underwent ODG, while in those undergoing LADG, the body weight change was $-2.7 \%,-4.3 \%$, and $-5.7 \%$, respectively (Aoyama et al. 2018). Patients who were treated with neoadjuvant chemotherapy before gastrectomy experienced a nadir weight loss about 10\%-15\% at 6 months after surgery (Davis et al. 2016). In China, Du et al. found that body weight loss of GC patients reached the lowest within 3 months after gastrectomy (Du et al. 2019).

Body weight loss has been associated with GC patient outcome. A more than $12 \%$ post-surgery body weight loss was strongly associated with poorer disease-free survival in GC (Kubo et al. 2016). In addition, body weight loss has not only been related with GC patient postoperative survival, but also associated with poorer quality of life. A cohort study followed up 76 patients undergoing curative gastric cancer resection and surviving at least two years without recurrence to examine the quality of life, and the results showed that body weight loss $10 \%$ or greater was associated with deterioration of all functional aspects of quality of life, as well as persistent pain, diarrhea, and nausea/vomiting (Climent et al. 2017). Furthermore, body weight loss reduce tolerance to treatment. Aoyama et al. found that body weight loss after gastrectomy in GC patients was an independent risk factor for the continuation of S-1 adjuvant chemotherapy (Aoyama et al. 2013). Therefore, considering the high prevalence of weight loss and its negative effect on outcome, it is necessary to identify the factors contributing to postoperative body weight change to improve the outcome and quality of life of the patients.

Body weight change in GC patents after gastrectomy involves tumor-, treatment-, and nutritionrelated factors. Identifying and predicting patients at risk of postoperative body weight loss are limited. Davis et al. analyzed factors contributing to postoperative weight loss, and found that the extend of weight loss after gastric cancer at one year depended on preoperative body mass index (BMI) and extent of gastric resection (Davis et al. 2016). Segami et al. detected that grade 2 or higher post-operative complication according to Clavien-Dindo classification and total gastrectomy were significant risk factors for severe body weight loss (more than $10 \%$ body weight loss) during the first month after surgery (Segami et al. 2018). Tanabe et al. found that higher 
80 preoperative BMI, total gastrectomy, and female sex were independent predictors of greater body 81 weight loss at the first one year mark after gastrectomy (Tanabe et al. 2017). These studies have 82 focused on the demographics, clinicopathology as well as treatment related factors on body weight 83 loss, but some findings of these studies were inconsistent. Besides, patient's nutrition knowledge, 84 attitude, and practice as internal impetus, were an important part of nutrition therapy. Patients with 85 higher nutrition literacy would take active actions in dietary intake, which may result in body 86 weight change. Furthermore, most of the studies on the factors affecting patient's body weight after 87 gastrectomy were based on the measured body weight value at a certain time or the difference 88

89

90

91

92

93

94

95

96

97

98

99

100

101

102

103

104

105

106

107

108

109

110

111

112

113

114

115

116

117

118

119 between the two measured values, and the analysis was inclined to a fixed time point. There is currently no multi time-point measurement to analyze the factors contributing to body weight change at multiple time points after gastrectomy in GC patients.

Hence, this study aimed to prospectively explore the influence of preoperative BMI, patient's knowledge, brief, practice score, demographics, clinicopathology, and treatment related factors on body weight change during three months after gastrectomy in patients with GC.

\section{Materials and methods}

\section{Study design}

Prospective longitudinal experimental design was used to identify factors contributing to body weight change during three months after gastrectomy in GC patients. Ethics approval of this study was obtained from Ruijin Hospital Ethics Committee, Shanghai Jiao Tong University School of Medicine (Shanghai, China).

\section{Participant recruitment}

GC Patients undergoing gastrectomy between January to March 2019 were identified in gastrointestinal surgery department prospectively. Volunteers meeting the following criteria were recruited: (1) diagnosed with GC; (2) scheduled for open gastrectomy; (3) aged 18 or above; (4) informed and agreed to participate in this study. Participates were excluded when they met condition below: (1) combined with other malignancies besides GC except distant metastasis; (2) palliative treatment; (3) recurrence within residual stomach; (4) patients with tube feeding after discharge. A written informed consent was obtained from all patients enrolled in the study. The sample size was estimated by $G^{*}$ power software (version 3.1) with three repeated measures, within factors design, a power of 0.80, significant level of 0.05, and effect size of 0.30.A sample size of 43 was required for analyzing body weight change during three months after gastrectomy by considering the attrition rate of $10 \%$.

\section{Data collection}

Volunteers were asked to complete a demographic questionnaire and a Digestive Cancer Patients Nutrition Knowledge, Attitude and Practice Questionnaire (DCNKAPQ). DCNKAPQ was designed to assess digestive cancer patients' nutrition knowledge, nutrition attitude, and nutrition practice with Cronbach's alpha 0.822 (Jing et al. 2016). Specifically, nutrition knowledge dimension contains 17 questions, one point would be taken when the question was given the right answer, otherwise 0 . Nutrition attitude dimension includes 5 items, which are scored on a 0-4 
120 response scale, with answers ranging from "strongly disagree" to "strongly agree". Nutrition 121 practice dimension covers 8 items, which are scored on a $0-4$ response scale, with answers ranging 122 from "never" to "always". Total scores of DCNKAPQ range from 0 to 69 , with score 0-17 from 123 nutrition knowledge, score 0-20 from nutrition attitude, and 0-32 from nutrition practice. The 124 demographic information included age, height, body weight, gender, marriage status, educational 125 level, and religious faith.

126 Data related with disease and treatment variables were collected from electronic patient record, 127 including cancer stage, cancer treatment, postoperative complication, nutrition support at home, 128 and comorbidity. The tumor staging was evaluated using the $7^{\text {th }}$ edition tumor-node-metastasis 129 (TNM). The Charlson comorbidity index (CCI) was applied to represent patient's comorbidity 130 severity. Categories of preoperative BMI were based on Asian standards proposed by WHO obesity expert advisory group in 2002, where BMI $<18.5 \mathrm{~kg} / \mathrm{m}^{2}$, BMI between $18.5 \mathrm{~kg} / \mathrm{m}^{2}$ to 22.99 $\mathrm{kg} / \mathrm{m}^{2}$, BMI between $23 \mathrm{~kg} / \mathrm{m}^{2}$ to $24.99 \mathrm{~kg} / \mathrm{m}^{2}$, and BMI $\geq 25 \mathrm{~kg} / \mathrm{m}^{2}$ indicate underweight, normal weight, overweight, and obesity, respectively. Body weight were collected at admission (T0), one month (T1), two month (T2), and three month (T3) after surgery. The body weight at four time points were reported by the patient self. the patients were required to wear the same outfit without accessories every time they measured the body weight for technical consistency. The percentage of body weight loss at each point was defined as follows: (preoperative body weight - body weight at each point after surgery) $* 100 \%$ / preoperative body weight.

139

140

\section{Statistical analysis}

141

142

Data analyses were performed by IBM SPSS 20.0. Measurement data meeting normal distribution were expressed as mean \pm standard deviation (SD), otherwise median combined with $25 \%$ quartiles and $75 \%$ quartiles. Categorical data were showed in the form of frequency or percentage. Generalized estimating equations (GEEs) were used to analyze the univariate and multivariable influence of demographic variables and clinical variables on body weight change in GC patients over time. Variables with at least a significant of $\mathrm{P}$ value less than 0.1 on univariate analysis (all characteristic, disease-, treatment-, nutritional variables) went on to be included in multivariate analysis. Quasi-likelihood under the independence model criterion (QIC) value is an index to evaluate whether working correlation matrix is appropriate for GEE. The lower the QIC value is, the fitter the GEE parameter estimation is. All statistics were based on two-sided test with level of significance set at 0.05 .

152

153

\section{Results}

156

\section{Baseline characteristics of the study population}

Eighty-two potentially eligible patients were available, but 27 patients did not meet the eligibility criteria, and 6 patients did not participate in follow up from T1 to T3. A total of 49 patients were involved in the study, including 1 patient lost at T1, but recovered at T2 and T3. There was no case 29-75 years old), the median preoperative body weight of male was $69.25(62.50,72.50) \mathrm{kg}$ in 
160

161

162

163

164

165

166

167

168

169

170

171

172

173

174

175

176

177

178

179

180

181

182

183

184

185

186

187

188

189

190

191

192

193

194

195

196

197

198

male GC patients and $57.00(51.00,61.00) \mathrm{kg}$ in female GC patients. The majority of them were married $(91.80 \%)$, without specific religious faith $(85.71 \%)$, and with a stage III or IV cancer (95.92\%). There were 13 cases with postoperative complications, including 6 cases with infection, 3 cases with delayed gastric empty, 1 cases with diarrhea, 1 with bleeding, 1 with duodenal stump fistula, and 1 with deep vein thrombosis. The median value of CCI, nutrition knowledge, attitude, and practice score were $5.00(3.00,6.00)$ points, $12.00(8.00,13.00)$ points, $15.00(14.00,18.00)$ points, and $21(18.00,23.00)$ points, respectively. Most of them were treated with neoadjuvant chemotherapy combined with gastrectomy $(81.63 \%)$, where the chemotherapy was mainly based on paclitaxel $(75.00 \%)$. Around half of the subjects underwent subtotal gastrectomy (51.02\%). After discharge, $57.14 \%$ patients took oral nutrition supplements (ONS) during the follow up (Table 1, Table 2)

\section{Body weight change before and during three months after gastrectomy}

The median body weight loss in GC patient at $\mathrm{T} 1$, $\mathrm{T} 2$, and $\mathrm{T} 3$ was $9.85 \%(7.41 \%, 11.76 \%), 12.14 \%$ $(8.70 \%, 12.14 \%)$, and $11.63 \%(8.51 \%, 14.40 \%)$, respectively, for the whole cohort (Fig.1). The GEE results showed a significant effect of time (Wald $\chi^{2}=333.917, \mathrm{P}<0.001$ ), indicating a decrease in body weight over time. According to the GEE parameter estimation, patient's body weight decreased by $9.2 \%$ at $\mathrm{T} 1$ (Wald $\chi^{2}=271.173, \mathrm{P}<0.001$ ), $11.0 \%$ at $\mathrm{T} 2$ (Wald $\chi^{2}=277.267$, $\mathrm{P}<0.001$ ), and $11.4 \%$ at T3 compared to baseline at T0 (Wald $\chi^{2}=284.076, \mathrm{P}<0.001$ ) (Table 3 ).

\section{Factors contributed to body weight change during three months after gastrectomy}

Each study variable entered GEE separately for univariate analysis. The results of the GEEs for univariate analysis showed that total gastrectomy patients had greater body weight loss compared with distal gastrectomy patients $(\beta=3.1 \%, \mathrm{P}=0.003)$, patients with postoperative complication was associated with greater body weight loss than patients without postoperative complication ( $\beta$ $=3.0 \%, \mathrm{P}=0.010), \mathrm{BMI} \geq 25 \mathrm{~kg} / \mathrm{m}^{2}$ was associated with greater body weight loss compared with BMI $<18.5 \mathrm{~kg} / \mathrm{m}^{2}(\beta=3.9 \%, \mathrm{P}=0.080)$, and higher nutrition practice score was associated with greater weight loss $(\beta=0.3 \%, P=0.070)$ (Table 4). Therefore, those variables with $P$ value less than 0.1 (operation type, preoperative BMI, post-operative complication, and nutrition practice score) were entered into GEE to do multivariable analysis. The results of GEE multivariable analysis indicated that surgery type and preoperative BMI were contributing factors of body weight change, while other variables, including postoperative complication and nutrition practice were not relevant. Compared with distal gastrectomy patients, total gastrectomy patients experienced greater body weight loss $(\beta=2.8 \%, \mathrm{P}=0.014)$. Compared with patient with $\mathrm{BMI}<18.5 \mathrm{~kg} / \mathrm{m}^{2}$, patients with $\mathrm{BMI} \geq 25 \mathrm{~kg} / \mathrm{m}^{2}$ experienced greater body weight loss $(\beta=4.5 \% \mathrm{P}=0.026)$ (Table 5).

\section{Discussion}

Body weight change after gastrectomy 
199

200

201

202

203

204

205

206

207

208

209

210

211

212

213

214

215

216

217

218

219

220

221

222

223

224

225

226

227

228

229

230

231

232

233

234

235

236

237

238

GC Patients often experience body weight loss after gastrectomy, which involves complicated mechanism and a lot of factors, including remnant stomach, malabsorption, hormonal changes, and life style (Aoyama 2019). Some scholars deemed that subtotal or total excision of gastric tissue negatively influence digestion and absorption of food inevitably. Also, operation itself may result in anorexia, thereby leading to body weight loss (Kim et al. 2019). Eom et al. found that postoperative body weight loss and anemia might originate from altered absorptive function and metabolic change after gastrectomy rather than decreased nutrient intake (Eom et al. 2018). Aoyama et al. revealed that mean body weight loss at 1 month reached $3.4 \mathrm{~kg}$ (5.90\% of body weight) compared with preoperative mean body weight in Japanese subjects (Aoyama et al. 2016). The team of Aoyama et al also found that mean body weight loss value at 1 month and 3 months after surgery were $6.5 \%$ and $9.0 \%$ respectively in the elderly, while $6.0 \%$ and $8.1 \%$ respectively in the non-elderly from the preoperative value, but the difference of weight loss over time between elderly and non-elderly was not significant(Aoyama et al. 2019). In China, researchers found that mean body weight loss up to 5.8-8.8 $\mathrm{kg}$ at 1 month (Shuai et al. 2019), and $6.33 \mathrm{~kg}$ at 3 months (Tang et al. 2018) after gastrectomy compared with preoperative body weight. Our results show that the percentage of body weight loss up reached $9.2 \%(5.67 \mathrm{~kg})$ at 1 month, $11.0 \%(6.83 \mathrm{~kg})$ at 2 months, and $11.4 \%(7.14 \mathrm{~kg})$ at 3 months after surgery from preoperative mean body weight. The higher body weight loss at three months in our study is possibly related the fact that most of the enrolled patients were advanced staged and underwent extensive chemotherapy.

The variation of postoperative body weight loss in different studies indicated that postoperative body weight was affected by a lot of factors. Aoyama et al. found that body weight loss during the first week after surgery was significantly greater than that during subsequent 3 weeks, and loss of lean body mass accounted for a significant part of body weight loss during the first week due to surgical stress (Aoyama et al. 2016). Abdiev et al. discovered that both fat and muscle mass reduction accounted for body weight loss during the first month after gastrectomy, and fat mass loss followed was responsible for weight loss after that period (Abdiev et al. 2011). Therefore, since energy deficiency and fat mass consumption rather than protein consumption are more prominent after discharge, continuous oral intake and exercise intervention should be given to GC patients after discharge to ensure the sufficient energy intake. In addition, body weight loss at 2 months was not significantly different from at 3 months after gastrectomy in this study, indicating that clinician should pay attention to the underlying causes of weight loss and direct nutrition intervention before 2 months after gastrectomy as soon as possible.

\section{Factors contributed to body weight change after gastrectomy}

The results of GEE showed significant main effect of preoperative BMI categories on body weight change after gastrectomy. Same as the findings in previous study (Aoyama et al. 2019; Shuai et al. 2019; Tang et al. 2018), we found that the percentage of body weight loss showed a downward trend as a whole within 3 months after gastrectomy, and the percentage of body weight loss within the first month postoperative period was significantly more than that in the third month postoperative. Similar to the findings in the study of Tanabe et al, who found that higher preoperative BMI, was independent predictors of greater body weight loss at the first one year

Peer] reviewing PDF | (2019:09:41731:3:0:NEW 20 May 2020) 
239 mark after gastrectomy (Tanabe et al. 2017). we found that BMI $\geq 25 \mathrm{~kg} / \mathrm{m}^{2}$ was risk factors to

240 body weight loss during three months after gastrectomy in GC patients. However, the result was 241 contract with the study by Park et al, who found that preoperative BMI $<23 \mathrm{~kg} / \mathrm{m}^{2}$ were associated 242 with severe weight loss after gastrectomy (Park et al. 2018). Similar to previous studies (Davis et 243 al. 2016; Nishigori et al. 2017; Segami et al. 2018), we found that total gastrectomy was a risk 244 factor for postoperative weight loss. Previous study observed that decreased calorie intake after 245 total gastrectomy compared with distal gastrectomy(Noguchi et al. 1992), which may explain total 246 gastrectomy patients experienced more body weight loss.

247 Similar to the findings in the study of Davis et al.(Davis et al. 2016), we found that postoperative 248 complication was not found to be independent factor on postoperative body weight loss in this 249 study. While Segami et al. found that surgical complication was a significant risk factor for severe 250 body weight loss the first month after gastrectomy(Segami et al. 2018). The conflict results prompt 251 the complexity of weight loss in GC patients after gastrectomy. As for higher nutrition knowledge, 252 attitude, and practice score were positively related with higher self-efficacy (Jing et al. 2016), 253 which is a vital theory to implement nutrition education, less weight loss was expected to appear 254 in patients with higher nutrition knowledge, attitude, and practice score in this study. However, 255 there was no significant effect of nutrition knowledge, attitude, and practice on postoperative body

256

257

258

259

260

261

262

263

264

265

266

267

268

269

270

271

272

273

274

275

276

277

278

279

280

281 weight loss. Consistent with some scholars' findings (Aoyama et al. 2019; Davis et al. 2016), our study verified that age was not a risk factor for postoperative body weight loss during 3 months after gastrectomy. Recently, Aoyama et al. found that postoperative lean body mass decreased significantly in elderly compared with non-elderly rather than body weight (Aoyama et al. 2019). There were some limitations in this study. Firstly, this was a single center study, $95.92 \%$ patients involved in our study were with cancer stage III or IV GC. So, the results that total gastrectomy and preoperative BMI were factors contributing to body weight change may not generalizable to patients with stage I or II. Secondly, we did not collect data about patient nutritional intake amount during 3 months after gastrectomy. So, the nutrition therapy factors on body weight change may be ignored in our study. Thirdly, the body weight at each point was reported by the patient self.

\section{Conclusion}

GC patients experienced significant body weight loss during three months after gastrectomy. Total gastrectomy and $\mathrm{BMI} \geq 25 \mathrm{~kg} / \mathrm{m}^{2}$ were risk factors to postoperative body weight loss for GC patients in this study. Given adverse effect of weight loss after surgery on overall survival and quality of life, the results suggested hinted that clinician should pay attention to postoperative nutrition status of GC patient undergoing total gastrectomy and obesity patients.

\section{References}

Abdiev S, Kodera Y, Fujiwara M, Koike M, Nakayama G, Ohashi N, Tanaka C, Sakamoto J, and Nakao A. 2011. Nutritional recovery after open and laparoscopic gastrectomies. Gastric Cancer 14:144-149. 10.1007/s10120-011-0021-9

Allemani C, Matsuda T, Di Carlo V, Harewood R, Matz M, Niksic M, Bonaventure A, Valkov M, Johnson CJ, Esteve J, Ogunbiyi OJ, Azevedo ESG, Chen WQ, Eser S, Engholm G, Stiller CA, Monnereau A, Woods RR, Visser O, Lim GH, Aitken J, Weir HK, and Coleman MP. 2018. Global surveillance of trends in cancer survival 2000-14 (CONCORD-3): analysis of individual records for 37513025 patients diagnosed with one of 18 cancers from 322 population-based registries in 71 countries. Lancet 391:1023-1075. 10.1016/s0140-

Peer] reviewing PDF | (2019:09:41731:3:0:NEW 20 May 2020) 
6736(17)33326-3

Aoyama T. 2019. Perioperative body composition changes in the multimodal treatment of gastrointestinal cancer. Surg Today. 10.1007/s00595-019-01815-8

Aoyama T, Kawabe T, Hirohito F, Hayashi T, Yamada T, Tsuchida K, Sato T, Oshima T, Rino Y, Masuda M, Ogata T, Cho H, and Yoshikawa T. 2016. Body composition analysis within 1 month after gastrectomy for gastric cancer. Gastric Cancer 19:645-650. 10.1007/s10120-015-0496-x

Aoyama T, Maezawa Y, Yoshikawa T, Segami K, Kano K, Hayashi T, Yamada T, Numata M, Goda M, Tamagawa H, Sato T, Yukawa N, Rino Y, Masuda M, Ogata T, Cho H, and Oshima T. 2019. Comparison of Weight and Body Composition After Gastrectomy Between Elderly and Non-elderly Patients With Gastric Cancer. In Vivo 33:221-227. 10.21873/invivo.11463

Aoyama T, Sato T, Hayashi T, Yamada T, Cho H, Ogata T, Oba K, and Yoshikawa T. 2018. Does a laparoscopic approach attenuate the body weight loss and lean body mass loss observed in open distal gastrectomy for gastric cancer? a single-institution exploratory analysis of the JCOG 0912 phase III trial. Gastric Cancer 21:345-352. 10.1007/s10120-017-0735-4

Aoyama T, Yoshikawa T, Shirai J, Hayashi T, Yamada T, Tsuchida K, Hasegawa S, Cho H, Yukawa N, Oshima T, Rino Y, Masuda M, and Tsuburaya A. 2013. Body weight loss after surgery is an independent risk factor for continuation of S-1 adjuvant chemotherapy for gastric cancer. Ann Surg Oncol 20:2000-2006. 10.1245/s10434-012-2776-6

Climent M, Munarriz M, Blazeby JM, Dorcaratto D, Ramon JM, Carrera MJ, Fontane L, Grande L, and Pera M. 2017. Weight loss and quality of life in patients surviving 2 years after gastric cancer resection. Eur J Surg Oncol 43:1337-1343. 10.1016/j.ejso.2017.01.239

Davis JL, Selby LV, Chou JF, Schattner M, Ilson DH, Capanu M, Brennan MF, Coit DG, and Strong VE. 2016. Patterns and Predictors of Weight Loss After Gastrectomy for Cancer. Ann Surg Oncol 23:1639-1645. 10.1245/s10434-015-5065-3

Du Zd, Zhang X, Wang Dp, Yu Yy, Zhang Wh, and Li Q. 2019. Relationship between body mass index and prognosis after radical gastrectomy. J Med Postgra 32:258-262. 10.16571/j.cnki.1008-8199.2019.03.007

Eom BW, Kim J, Kim DH, Kim YI, Yoon HM, Cho SJ, Lee JY, Kim CG, Choi IJ, Kim YW, Nam BH, and Ryu KW. 2018. Recovery of Food Intake after Gastrectomy for Gastric Cancer: Based on a Large-Scale Gastric Cancer Cohort. Dig Surg 35:220-229. 10.1159/000477779

Ferlay J, Soerjomataram I, Dikshit R, Eser S, Mathers C, Rebelo M, Parkin DM, Forman D, and Bray F. 2015. Cancer incidence and mortality worldwide: sources, methods and major patterns in GLOBOCAN 2012. Int J Cancer 136:E359-386. 10.1002/ijc.29210

Jing Z, Wei-li W, and Xin-qiong Z. 2016. Investigation and analysis on nutrition knowledge, attitude and practice of digestive cancer patients. Parenteral \& Enteral Nutrition 23:226-228,236. 10.16151/j.1007810x.2016.04.009

Kim YN, Choi YY, An JY, Choi MG, Lee JH, Sohn TS, Bae JM, Noh SH, and Kim S. 2019. Comparison of Postoperative Nutritional Status after Distal Gastrectomy for Gastric Cancer Using Three Reconstructive Methods: a Multicenter Study of over 1300 Patients. J Gastrointest Surg. 10.1007/s11605-019-04301-1

Kubo H, Komatsu S, Ichikawa D, Kawaguchi T, Kosuga T, Okamoto K, Konishi H, Shiozaki A, Fujiwara H, and Otsuji E. 2016. Impact of Body Weight Loss on Recurrence After Curative Gastrectomy for Gastric Cancer. Anticancer Res 36:807-813.

Nishigori T, Okabe H, Tsunoda S, Shinohara H, Obama K, Hosogi H, Hisamori S, Miyazaki K, Nakayama T, and Sakai Y. 2017. Superiority of laparoscopic proximal gastrectomy with hand-sewn esophagogastrostomy over total gastrectomy in improving postoperative body weight loss and quality of life. Surg Endosc 31:36643672. 10.1007/s00464-016-5403-y

Noguchi Y, Tsuburaya A, Makino T, Fukuzawa K, Nomura K, Yoshikawa T, Minn XH, Imada T, and Matsumoto A. 1992. Metabolic alterations in totally gastrectomised patients - Caloric intake and energy consumption. Asian J Surg 15:97-102.

Park YS, Park DJ, Lee Y, Park KB, Min SH, Ahn SH, and Kim HH. 2018. Prognostic Roles of Perioperative Body Mass Index and Weight Loss in the Long-Term Survival of Gastric Cancer Patients. Cancer Epidemiol Biomarkers Prev 27:955-962. 10.1158/1055-9965.epi-18-0122

Segami K, Aoyama T, Kano K, Maezawa Y, Nakajima T, Ikeda K, Sato T, Fujikawa H, Hayashi T, Yamada T, Oshima T, Yukawa N, Rino Y, Masuda M, Ogata T, Cho H, and Yoshikawa T. 2018. Risk factors for severe weight loss at 1 month after gastrectomy for gastric cancer. Asian J Surg 41:349-355. 10.1016/j.asjsur.2017.02.005

Shuai M, Hao L, Fu-hai M, Yang L, Wen-zhe K, Wei-kun L, Cheng-long Y, Yan Q, Ya-nan F, Hong-liang W, and Yan-tao T. 2019. Application value of enteral nutrition preparation in perioperative rapid rehabilitation of

Peer] reviewing PDF | (2019:09:41731:3:0:NEW 20 May 2020) 
patients with gastric cancer. Chinese Journal of the Frontiers of Medical Science (Electronic Version) 11:1417. $10.12037 / y x q y .2019 .02-04$

Tanabe K, Takahashi M, Urushihara T, Nakamura Y, Yamada M, Lee SW, Tanaka S, Miki A, Ikeda M, and Nakada K. 2017. Predictive factors for body weight loss and its impact on quality of life following gastrectomy. World J Gastroenterol 23:4823-4830. 10.3748/wjg.v23.i26.4823

Tang Xl, Zhang T, Wang Gr, Xu R, Wang J, Li Yf, and Lv Jh. 2018. The effects of goal-directed nutrition therapy model on nutritional status and postoperative rehabilitation in gastric cancer patients. Electron J Metab Nutr Cancer 5:297-302. 10.16689/j.cnki.cn11-9349/r.2018.03.016

Zeng H, Chen W, Zheng R, Zhang S, Ji JS, Zou X, Xia C, Sun K, Yang Z, Li H, Wang N, Han R, Liu S, Li H, Mu H, He Y, Xu Y, Fu Z, Zhou Y, Jiang J, Yang Y, Chen J, Wei K, Fan D, Wang J, Fu F, Zhao D, Song G, Chen J, Jiang C, Zhou X, Gu X, Jin F, Li Q, Li Y, Wu T, Yan C, Dong J, Hua Z, Baade P, Bray F, Jemal A, Yu $\mathrm{XQ}$, and He J. 2018. Changing cancer survival in China during 2003-15: a pooled analysis of 17 populationbased cancer registries. Lancet Glob Health 6:e555-e567. 10.1016/s2214-109x(18)30127-x 


\section{Table 1 (on next page)}

Demographic, clinicopathology, treatment characteristics of patients with GC.

BMI: body mass index, ONS: oral nutritional supplements 
1 Table 1 Demographic, clinicopathology, treatment characteristics of patients with GC.

\begin{tabular}{|c|c|}
\hline Variables & $\mathrm{N}$ (percentage) \\
\hline \multicolumn{2}{|l|}{ Age } \\
\hline$<65 \mathrm{y}$ & $37(75.51 \%)$ \\
\hline$\geq 65 \mathrm{y}$ & $12(24.49 \%)$ \\
\hline \multicolumn{2}{|l|}{ Gender } \\
\hline Male & $22(44.90 \%)$ \\
\hline Female & $27(55.10 \%)$ \\
\hline \multicolumn{2}{|l|}{ Marriage status } \\
\hline Single & $1(2.04 \%)$ \\
\hline Married & $45(91.84 \%)$ \\
\hline Devoiced or widowed & $3(6.12 \%)$ \\
\hline \multicolumn{2}{|l|}{ Education level } \\
\hline Elementary or below & $9(18.37 \%)$ \\
\hline Middle & $8(16.33 \%)$ \\
\hline High & $11(22.45 \%)$ \\
\hline College or above & $21(42.86 \%)$ \\
\hline \multicolumn{2}{|l|}{ Religion } \\
\hline None & $42(85.71 \%)$ \\
\hline Buddhism & $7(14.29 \%)$ \\
\hline \multicolumn{2}{|l|}{ Preoperative BMI } \\
\hline Underweight & $5(10.20 \%)$ \\
\hline Normal weight & $21(42.86 \%)$ \\
\hline Overweight & $10(20.41 \%)$ \\
\hline Obesity & $13(26.53 \%)$ \\
\hline \multicolumn{2}{|l|}{ Cancer stage } \\
\hline II & $2(4.08 \%)$ \\
\hline III & $28(57.14 \%)$ \\
\hline IV & $19(38.78 \%)$ \\
\hline \multicolumn{2}{|l|}{ Cancer therapy } \\
\hline Surgery & $1(2.04 \%)$ \\
\hline Surgery + Chemotherapy & $8(16.33 \%)$ \\
\hline Neoadjuvant chemotherapy + Surgery & $40(81.63 \%)$ \\
\hline \multicolumn{2}{|l|}{ Type of operation } \\
\hline Distal & $25(51.02 \%)$ \\
\hline Total & $24(48.98 \%)$ \\
\hline \multicolumn{2}{|l|}{ Type of chemotherapy } \\
\hline Base on paclitaxel & $37(75.51 \%)$ \\
\hline Base on xeloda & $1(2.04 \%)$ \\
\hline Base on oxaliplatin & $4(8.16 \%)$ \\
\hline
\end{tabular}




\begin{tabular}{ll} 
Base on irinotecan & $1(2.04 \%)$ \\
Base on S-1 & $6(12.24 \%)$ \\
ONS & \\
Without & $28(57.14 \%)$ \\
With & $21(42.86 \%)$ \\
Complication & \\
Without & $36(73.47 \%)$ \\
With & $13(26.53 \%)$ \\
\hline
\end{tabular}

BMI: body mass index, ONS: oral nutritional supplements 


\section{Table 2 (on next page)}

$\mathrm{CCl}$ and KAP characteristics of patients with GC.

CCI: Charlson comorbidity index, KAP: Nutrition Knowledge, Attitude and Practice 
1 Table 2 CCI and KAP characteristics of patients with GC.

\begin{tabular}{llll}
\hline Variables & & Median & 25\%quartiles, 75\%quartiles \\
\hline CCI & & 5.00 & $3.00,6.00$ \\
KAP & Knowledge & 12.00 & $8.00,13.00$ \\
& Attitude & 15.00 & $14.00,18.00$ \\
& Practice & 21.00 & $18.00,23.00$
\end{tabular}

2 CCI: Charlson comorbidity index, KAP: Nutrition Knowledge, Attitude and Practice 3 


\section{Table 3 (on next page)}

Percentage of body weight change over time before and during 3 months after gastrectomy in GC patients

T0: before surgery, T1: 1 month after gastrectomy, T2: 2 months after gastrectomy, T3: 3

months after gastrectomy, $\beta$ : partial regression coefficient, SE: standard error, $\mathrm{Cl}$ : confidence interval 
1 Table 3 Percentage of body weight change over time before and during 3 months after gastrectomy in GC 2 patients

\begin{tabular}{lllllll}
\hline Variables & $\beta$ & SE & \multicolumn{2}{c}{$95 \% \mathrm{CI}$} & Wald $\chi^{2}$ & $\mathrm{P}$ \\
\cline { 4 - 5 } & & & lower & upper & & \\
\hline Time & & & & & 333.917 & $<0.001$ \\
T3 & $11.4 \%$ & $6.8 \%$ & $10.1 \%$ & $12.8 \%$ & 284.076 & $<0.001$ \\
T2 & $11.0 \%$ & $6.6 \%$ & $9.7 \%$ & $12.3 \%$ & 277.267 & $<0.001$ \\
T1 & $9.2 \%$ & $5.6 \%$ & $8.1 \%$ & $10.3 \%$ & 271.173 & $<0.001$ \\
T0 & - & & & & & \\
\hline
\end{tabular}

3 T0: before surgery, T1: 1 month after gastrectomy, T2: 2 months after gastrectomy, T3: 3 months after 4 gastrectomy, $\beta$ : partial regression coefficient, SE: standard error, $\mathrm{CI}$ : confidence interval 


\section{Table 4(on next page)}

Association of study variables with body weight change three months after gastrectomy in univariate analysis

ONS: oral nutritional supplements, BMI: body mass index, $\mathrm{CCl}$ : Charlson comorbidity index, $\beta$ : partial regression coefficient, SE: standard error, $\mathrm{Cl}$ : confidence interval 
1 Table 4 Association of study variables with body weight change three months after gastrectomy in 2 univariate analysis

\begin{tabular}{|c|c|c|c|c|c|c|}
\hline \multirow[t]{2}{*}{ Variables } & \multirow[t]{2}{*}{$\beta$} & \multirow[t]{2}{*}{$\mathrm{SE}$} & \multicolumn{2}{|c|}{$95 \% \mathrm{CI}$} & \multirow[t]{2}{*}{ Wald $\chi^{2}$} & \multirow[t]{2}{*}{$P$} \\
\hline & & & lower & upper & & \\
\hline \multicolumn{7}{|l|}{ Age } \\
\hline$<65 \mathrm{y}$ & $1.4 \%$ & $1.4 \%$ & $-1.3 \%$ & $4.2 \%$ & 1.071 & 0.301 \\
\hline$\geq 65 y$ & - & & & & & \\
\hline \multicolumn{7}{|l|}{ Gender } \\
\hline Female & $<0.1 \%$ & $1.1 \%$ & $-2.2 \%$ & $2.3 \%$ & 0.001 & 0.977 \\
\hline Male & - & & & & & \\
\hline \multicolumn{7}{|l|}{ Marriage status } \\
\hline Single, or devoiced or widowed & $-1.7 \%$ & $2.5 \%$ & $-6.5 \%$ & $3.1 \%$ & 0.472 & 0.492 \\
\hline Married & - & & & & & \\
\hline Education level & & & & & 2.275 & 0.321 \\
\hline Middle or below & $1.9 \%$ & $12.8 \%$ & $-0.6 \%$ & $4.4 \%$ & 2.197 & 0.138 \\
\hline High & $1.4 \%$ & $1.5 \%$ & $-1.5 \%$ & $4.3 \%$ & 0.847 & 0.358 \\
\hline College or above & - & & & & & \\
\hline \multicolumn{7}{|l|}{ Religion } \\
\hline Buddhism & $2.0 \%$ & $1.6 \%$ & $-1.0 \%$ & $5.0 \%$ & 1.645 & 0.200 \\
\hline No religion & - & & & & & \\
\hline Cancer stage & & & & & 1.514 & 0.469 \\
\hline IV & $3.3 \%$ & $3.1 \%$ & $-2.7 \%$ & $9.4 \%$ & 1.158 & 0.282 \\
\hline III & $2.2 \%$ & $3.0 \%$ & $-3.6 \%$ & $8.1 \%$ & 0.550 & 0.458 \\
\hline II & - & & & & & \\
\hline \multicolumn{7}{|l|}{ Type of operation } \\
\hline Total & $3.1 \%$ & $1.1 \%$ & $1.0 \%$ & $5.2 \%$ & 8.551 & 0.003 \\
\hline Distal & - & & & & & \\
\hline Treatment type & & & & & 0.585 & 0.747 \\
\hline Surgery & $0.4 \%$ & $0.7 \%$ & $-0.8 \%$ & $1.7 \%$ & 0.442 & 0.506 \\
\hline Surgery + Chemotherapy & $-0.1 \%$ & $1.7 \%$ & $-3.4 \%$ & $3.1 \%$ & 0.008 & 0.929 \\
\hline Neoadjuvant chemotherapy + & - & & & & & \\
\hline \multicolumn{7}{|l|}{ Surgery } \\
\hline \multicolumn{7}{|l|}{ ONS } \\
\hline With & $0.9 \%$ & $1.1 \%$ & $-1.3 \%$ & $3.2 \%$ & 0.667 & 0.414 \\
\hline Without & - & & & & & \\
\hline Preoperative BMI & & & & & 8.993 & 0.029 \\
\hline Obesity & $3.9 \%$ & $2.2 \%$ & $-0.5 \%$ & $8.2 \%$ & 3.063 & 0.080 \\
\hline Overweight & $0.8 \%$ & $2.5 \%$ & $-4.1 \%$ & $-5.7 \%$ & 0.092 & 0.761 \\
\hline Normal weight & $1.6 \%$ & $2.3 \%$ & $-3.0 \%$ & $-6.1 \%$ & 0.456 & 0.499 \\
\hline Underweight & - & & & & & \\
\hline
\end{tabular}




\section{Complication}

With

$3.0 \%$

$1.1 \%$

$0.7 \%$

$5.2 \%$

6.700

0.010

Without

CCI

$0.2 \%$

$0.2 \%$

$-0.2 \% \quad 0.6 \%$

0.878

0.349

Knowledge

$0.1 \%$

$0.1 \% \quad-0.2 \% \quad 0.3 \%$

0.260

0.610

Attitude

$0.3 \%$

$0.2 \%$

$-0.1 \% \quad 0.6 \%$

2.012

0.156

Practice

$0.3 \%$

$0.2 \%$

$<0.1 \% \quad 0.6 \%$

3.288

0.070

3

4

5

6

7

8 


\section{Table 5 (on next page)}

Association of study variables with body weight change three months after gastrectomy in multivariable analysis

T1: 1 month after gastrectomy, T2: 2 months after gastrectomy, T3: 3 months after gastrectomy, BMI: body mass index, $\beta$ : partial regression coefficient, SE: standard error, $\mathrm{Cl}$ : confidence interval 
1 Table 5 Association of study variables with body weight change three months after gastrectomy in 2 multivariable analysis

\begin{tabular}{|c|c|c|c|c|c|c|}
\hline \multirow[t]{2}{*}{ Variables } & \multirow[t]{2}{*}{$\beta$} & \multirow[t]{2}{*}{ SE } & \multicolumn{2}{|c|}{$95 \% \mathrm{CI}$} & \multirow[t]{2}{*}{ Wald $\chi^{2}$} & \multirow[t]{2}{*}{$P$} \\
\hline & & & lower & upper & & \\
\hline Intercept & $11.2 \%$ & $2.9 \%$ & $5.5 \%$ & $7.0 \%$ & 14.624 & $<0.001$ \\
\hline Time & & & & & 19.780 & $<0.001$ \\
\hline $\mathrm{T} 1$ & $-0.2 \%$ & $0.5 \%$ & $-3.2 \%$ & $-1.2 \%$ & 19.438 & $<0.001$ \\
\hline $\mathrm{T} 2$ & $-0.4 \%$ & $0.3 \%$ & $-1.0 \%$ & $0.2 \%$ & 1.999 & 0.157 \\
\hline $\mathrm{T} 3$ & - & & & & & \\
\hline Preoperative BMI & & & & & 12.662 & 0.005 \\
\hline Obesity & $4.5 \%$ & $2.1 \%$ & $0.5 \%$ & $8.4 \%$ & 4.928 & 0.026 \\
\hline Overweight & $1.9 \%$ & $2.3 \%$ & $-2.6 \%$ & $6.3 \%$ & 0.673 & 0.412 \\
\hline Normal weight & $1.3 \%$ & $2.0 \%$ & $-2.6 \%$ & $5.3 \%$ & 0.430 & 0.512 \\
\hline Underweight & - & & & & & \\
\hline \multicolumn{7}{|l|}{ Type of operation } \\
\hline Total & $2.8 \%$ & $1.2 \%$ & $0.6 \%$ & $5.1 \%$ & 6.027 & 0.014 \\
\hline Distal & - & & & & & \\
\hline \multicolumn{7}{|l|}{ Complication } \\
\hline With & $1.0 \%$ & $1.3 \%$ & $-1.6 \%$ & $3.6 \%$ & 0.533 & 0.465 \\
\hline Without & - & & & & & \\
\hline Practice & $0.2 \%$ & $0.1 \%$ & $<0.1 \%$ & $0.5 \%$ & 3.010 & 0.083 \\
\hline
\end{tabular}

3 T1: 1 month after gastrectomy, T2: 2 months after gastrectomy, T3: 3 months after gastrectomy, BMI: body 4 mass index, $\beta$ : partial regression coefficient, SE: standard error, CI: confidence interval 
Figure 1

The loss of body weight after gastrectomy at $\mathrm{T} 1, \mathrm{~T} 2$, and $\mathrm{T} 3$ in this study.

T0: before surgery, T1: 1 month after gastrectomy, T2: 2 months after gastrectomy, T3: 3 months after gastrectomy, Bars: Median, boxes: lower and upper quartiles, lines: minimum and maximum.

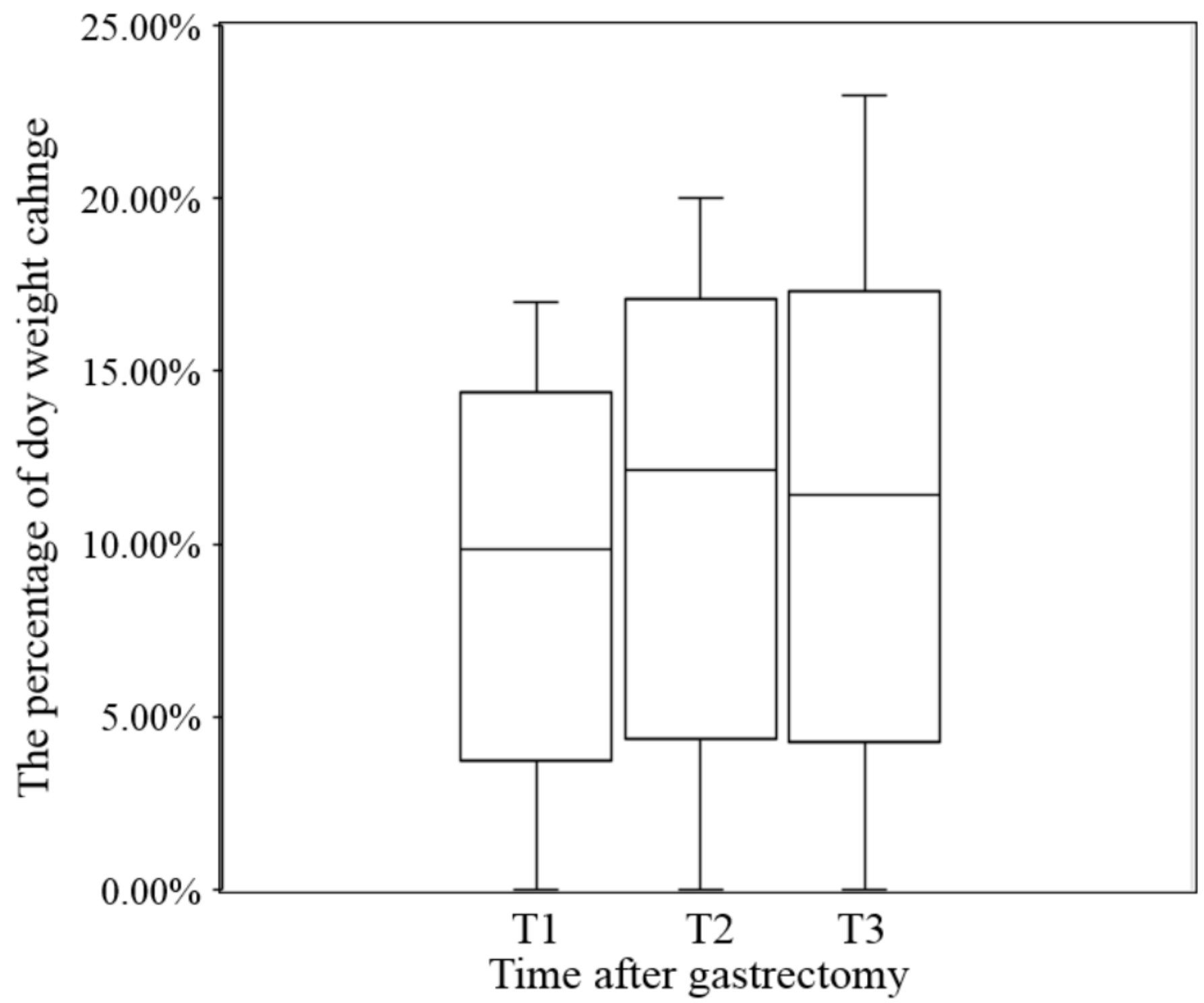

